\title{
Brain death, the determination of brain death, and member guidance for brain death accommodation requests
}

\author{
AAN position statement
}

James A. Russell, DO, MS, Leon G. Epstein, MD, David M. Greer, MD, MA, Matthew Kirschen, MD, PhD, Michael A. Rubin, MD, MA, and Ariane Lewis, MD

Neurology ${ }^{\circledR}$ 2019;92:228-232. doi:10.1212/WNL.0000000000006750

\section{Abstract}

The American Academy of Neurology holds the following positions regarding brain death and its determination, and provides the following guidance to its members who encounter resistance to brain death, its determination, or requests for accommodation including continued use of organ support technology despite neurologic determination of death.

The medical profession's ability to determine death accurately, whether caused by irreversible brain or circulatory failure, is integral to the maintenance of the public trust in the profession's fulfillment of its fiduciary responsibility to its patients.

In 1981, the Uniform Determination of Death Act (UDDA) was published, a statute proposed by the American Bar Association, the American Medical Association, the National Conference of Commissioners on Uniform State Laws, and the President's Commission for the Study of Ethical Problems in Medicine and Biomedical and Behavioral Research. ${ }^{1-4}$ The UDDA's position served to address a societal problem created in the mid20th century as a consequence of the development of mechanical ventilation and other organ-sustaining technologies. As a result, irreversibly brain-injured individuals could have their physiologic existence sustained for variable periods of time. The purpose of the UDDA was to establish a uniform definition of death, determined by "acceptable medical standards," that was "clear and socially accepted," with the intention of being adopted in every US jurisdiction. The President's Commission and the UDDA considered death to be a "unitary phenomenon" regardless of causation, resulting from either irreversible failure of brain or circulatory function. It recognized the "biological facts of universal applicability," while seeking to "protect patients against ill-advised idiosyncratic pronouncements of death." The UDDA perspectives are supported by a preponderance of medical and legal authorities, the original UDDA wording having been supported by the American Academy of Neurology (AAN).,

Brain death is death of the individual due to irreversible loss of function to the entire brain. Otherwise known as death by neurologic criteria, it is accepted as legal death in all US jurisdictions, as determined by one or more medical professionals through application of accepted medical standards. ${ }^{5-11}$ The standards for adult and pediatric patients that are currently widely accepted by the medical profession are the 2010 Evidence-Based Guideline Update: Determining Brain Death in Adults (endorsed by the Neurocritical Care Society, the Child Neurology Society, the Radiologic Society of North America, and the American College of Radiology) and the 2011 Guidelines for the Determination of
Correspondence

Dr. J.A. Russell

james.a.russell@lahey.org

\section{MORE ONLINE}

ค Podcast

Dr. Jason Crowell talks with Dr. James Russell about his paper on brain death, the determination of brain death, and member guidance for brain death accommodation requests.

NPub.org/we188x

AMERICAN ACADEMY OF NEUROLOGY

From the Division of Neurology (J.A.R.), Lahey Hospital and Medical Center, Burlington; Department of Neurology (D.M.G.), Boston University, MA; Neurology Division (L.G.E.), Ann \& Robert H. Lurie Children's Hospital of Chicago, IL; Neurology Division (M.P.K.), The Children's Hospital of Philadelphia, PA; Department of Neurology and Neurotherapeutics (M.R.), UT Southwestern Medical Center, Dallas, TX; and Neurology Department (A.L.), New York University Langone Center, New York.

Go to Neurology.org/N for full disclosures. Funding information and disclosures deemed relevant by the authors, if any, are provided at the end of the article.

This position document has been endorsed by the American Neurologic Association and the Child Neurology Society. 


\section{Glossary}

AAN = American Academy of Neurology; AAP = American Academy of Pediatrics; CNS = Child Neurology Society; SCCM = Society of Critical Care Medicine; UDDA = Uniform Determination of Death Act.

Brain Death in Infants and Children published by the Pediatric Section of the Society of Critical Care Medicine (SCCM), the Sections of Neurology and Critical Care of the American Academy of Pediatrics (AAP), and the Child Neurology Society (CNS) (collectively, Brain Death Guidelines). ${ }^{5,7,9-11}$ These widely accepted medical standards for the determination of brain death remain legally unspecified in all but one jurisdiction (Nevada). ${ }^{12}$

While the UDDA prudently deferred to the medical profession to identify the "accepted medical standards," the lack of specificity in most states' laws, coupled with inconsistency among institutional brain death protocols, has contributed to differing interpretations by the courts in a few high-profile cases. These serve to promote ambiguity regarding the criteria for brain death determination and to erode the authority of physicians to determine death by neurologic criteria without the informed consent of a patient's surrogate. ${ }^{5,7,8,12-16}$ As anticipated by the UDDA, these cases exemplify how the lack of specificity and uniformity may perpetuate a minority opinion regarding the determination of brain death, which in turn threatens to promote negotiated or "ill-advised idiosyncratic" standards for death determination, an undesired template for professional organizations or public policy. ${ }^{1}$

The AAN is unaware of any cases in which compliant application of the Brain Death Guidelines led to inaccurate determination of death with return of any brain function, including consciousness, brainstem reflexes, or ventilatory effort. The AAN is unaware of the existence of other clinical or ancillary testing standards that would surpass the Brain Death Guidelines in accuracy. ${ }^{10,11}$ Further, the AAN, as supported by its membership, believes that a specific, uniform standard for the determination of brain death is critically important to promote the highest quality patient-centered neurologic and end-of-life care, and by doing so, enhance the public trust. ${ }^{17}$ Accordingly, the AAN endorses the position maintained by the UDDA that the clinical standards for the determination of brain death fall within the purview of the medical profession. Furthermore, it endorses legislation modeled after the Nevada statute, which specifically defers to current adult and pediatric Brain Death Guidelines and any future updates. ${ }^{12,13,18}$ The Nevada statute eliminates uncertainty over what the acceptable medical standards are and defers to the medical profession to continue research to ensure that Brain Death Guidelines provide optimal specificity and sensitivity in brain death determination..$^{10,11,18}$

To obtain, maintain, and bolster the public trust, in consideration of its mission to promote the highest-quality patient- centered neurologic care, and in support of its vision to be indispensable to its members, the AAN holds the following positions and provides the following guidance regarding brain death and its determination. This guidance is provided in response to an AAN-sponsored survey of its members, in which respondents requested that clear, simple, and universal guidelines be provided on how to respond to objections to determination of death by neurologic criteria and requests for temporary or indefinite accommodation. The guidance provided herein, as requested by AAN members, is lawful, and intended to be disseminated to the medical profession and the public. ${ }^{17}$ This position is a byproduct of the goals identified by a brain death summit, sponsored by the AAN in the autumn of 2016, and the Brain Death Working Group spawned by that meeting. ${ }^{19}$

\section{Brain death as death}

The AAN endorses the UDDA definition that brain death has occurred when the irreversible loss of all functions of the entire brain, including the brainstem, has been determined by the demonstration of complete loss of consciousness (coma), brainstem reflexes, and the independent capacity for ventilatory drive (apnea), in the absence of any factors that imply possible reversibility. It recognizes that neuroendocrine function may persist in patients with irreversible injury to the brain and brainstem, potentially due to the vascular anatomy of the hypothalamus and pituitary, providing a potential sanctuary for this region from the adverse effects of increased intracranial pressure and consequent ischemia that may otherwise irreversibly injure the remainder of the intracranial contents. ${ }^{20,21}$ It endorses that clinical assessment is the foundation of brain death determination, and that the primary role of ancillary testing is to serve as a surrogate means of assessment when requisite components of clinical brain death evaluation cannot be ascertained.

The AAN acknowledges the medical and legal framework provided by the UDDA; that is, that brain death is the equivalent of circulatory death, a position endorsed by $93 \%$ of its surveyed members. ${ }^{17}$ It does so with the recognition that in both circulatory and brain death, the demise of other organ systems is inevitable without the permanent application of organ-sustaining technology to maintain perfusion and ventilation, respectively. Just as proof of demise of every myocardial cell is not requisite for the determination of circulatory death, proof of demise of every neuron is not required to demonstrate irreversible loss of whole brain function. 


\section{Uniformity of brain death determination}

The AAN believes that the public trust in accurate brain death determination and the ability of the courts to adjudicate contentious cases will be enhanced by uniform brain death laws, policies, and practices. ${ }^{6,16}$ Accordingly, the AAN supports legislation modeled after the Nevada statute and efforts to develop (1) uniform institutional policies for brain death determination within US medical facilities, (2) training programs for physicians who determine brain death, (3) credentialing mechanisms for physicians involved in brain death determination, regardless of specialty, (4) institutional policies that ensure compliance with the medical standards for brain death determination by physicians, (5) research that enhances the brain death knowledge base and the accuracy of its determination, and (6) enhanced professional and public education regarding these considerations.

\section{AAN positions, recommendations, and guidance regarding requests for accommodation}

Physicians responsible for the care of severely brain-injured patients may encounter requests by loved ones and lawful patient surrogates to delay or prohibit discontinuation of organ-sustaining technology once an individual has been determined to be dead by accepted diagnostic criteria, or in some cases to encounter resistance to performance of the brain death examination. ${ }^{7,8,12,14,22}$ Requests for accommodation may be temporary or indefinite. The genesis may originate from a lack of understanding or acceptance of brain death, potentially modified by emotional or religious influences, or other legal or social considerations. ${ }^{7,14,22}$ The AAN, although respectful of the autonomy of patients and those acting on their behalf, recognizes that, both legally and ethically, autonomy is not absolute and does not include the right to receive desired but unjustified medical treatment. Consequently, the AAN acknowledges that its members and the institutions in which they work may be conflicted in attempting to resolve these requests, and may benefit from the following recommendations and guidance. ${ }^{17,22}$

\section{AAN position on brain death and its determination}

- The AAN endorses the perspective of the UDDA that brain death has occurred when the irreversible loss of all functions of the entire brain including the brainstem has been determined. However, the AAN endorses the belief that preserved neuroendocrine function may be present despite irreversible injury of the cerebral hemispheres and brainstem and is not inconsistent with the whole brain standard of death. ${ }^{17,20,21,23-25}$

- The AAN recognizes that the fundamental concept underlying the accurate determination of brain death is the irreversibility of injury to the cerebral hemispheres and brainstem.

- The AAN endorses that brain death determination is fundamentally a clinical assessment, and that the primary role of ancillary testing is to serve as a surrogate means of assessment when requisite components of the clinical brain death evaluation cannot be adequately performed or interpreted.

- The AAN recognizes that the guidelines provided by the American Academy of Neurology for adults, and the Pediatric Section of the SCCM, the Section on Critical Care of the AAP, and the CNS for the pediatric population represent the recognized medical standards for brain death determination. ${ }^{8,9}$

- The AAN endorses that should an AAN member be opposed to determination of brain death, based on religious or moral conscience, he or she should seek transfer of this responsibility to another qualified physician. Conversely, the AAN endorses that a member who is opposed to indefinite accommodation based on religious or moral conscience should be allowed to transfer the care of a deceased individual to another individual if possible, without reprisal, if continued care is mandated by law or institutional policy.

\section{AAN recommendations to enhance the public trust in brain death and its determination}

- The AAN endorses that all brain death examinations should be undertaken with the premise that the patient is alive and with that expectation being explicitly communicated to loved ones and lawful surrogates. The AAN recommends that unless precluded by exceptional circumstance, the brain death examination follow rather than precede a candid conversation between the physician responsible for the care of the patient and the patient's lawful surrogate regarding the medical status and prognosis of the patient in whom brain death is being considered.

- The AAN recognizes that each case is unique and requires a sensitive and empathetic inquiry intended to establish a relationship of trust. Accordingly, the AAN endorses efforts to identify the underlying reasons for opposition to brain death determination or requests for indefinite accommodation. The goal of doing so is to reconcile differences in a manner satisfactory to loved ones and lawful surrogates, the medical care team, and the institution in which they work. ${ }^{7,22,26}$

- The AAN endorses continued research intended to ensure that pediatric and adult guidelines accurately identify brain death in all circumstances and are as uniform as possible. These efforts would ideally include the development of a single guideline for both pediatric and adult brain death determination, while respecting the physiologic differences between developing and mature brains. ${ }^{24}$

- The AAN endorses the development of uniform policies within US health care institutions that address brain death and its determination.

- The AAN encourages the mandatory incorporation of brain death determination training within neurology and other relevant training programs with the goal of establishing uniform competence in brain death determination.

- The AAN endorses the development of institutional programs that credential competence in brain death determination, and that monitor compliance with the aforementioned guidelines. 
- The AAN endorses witness of the brain death examination by loved ones should the patient's medical caregivers believe that understanding and acceptance of brain death would be improved by this opportunity.

- The AAN supports development of programs that provide accurate public and professional education regarding brain death and its determination. ${ }^{17}$

- Although the AAN strongly endorses the beneficence provided by organ donation, it believes that the primary professional responsibility of its members is to their patients, fulfilled by accurate and timely diagnosis.

\section{AAN guidance to its members responding to requests for accommodation}

- The AAN desires to provide lawful guidance for its members faced with requests for accommodation. These requests include objections to brain death determination or the withdrawal of organ-sustaining technology. The AAN strives to achieve reconciliation of the positions of all stakeholders without undermining the professional responsibility of neurologists acting in the best interest of their patients. ${ }^{7,16}$

- The AAN is respectful of and sympathetic toward requests for limited accommodation based on reasonable and sincere social, moral, cultural, and religious considerations, recognizing that beliefs vary not only between but within religions, and understanding that such requests must be based on the values of the patient and not those of loved ones or other surrogate decision-makers. ${ }^{7}, 15,17,22,27,28$

- At the same time, the AAN acknowledges that there is no ethical obligation to provide medical treatment to a deceased person. In the United States, with the exception of New Jersey, there is no legal obligation to provide indefinite accommodation with continued application of organ-sustaining technology to the deceased. The AAN recognizes the potential for harm to the patient, the family, or other patients and the health care team from indefinite accommodation. These potential harms include mistreatment of the newly dead, deprivation of dignity, provision of false hope with resultant distrust, prolongation of the grieving process, undermining of the professional responsibility of the physician to achieve a timely and accurate diagnosis, and an anticipated societal harm arising from a negotiated and inconsistent standard of death. .7,22,29-31 $^{2}$

- The AAN encourages members to include provisions for management of requests for accommodation in institutional brain death protocols addressing the conditions and time frame for accommodation.

- Despite its respect for cultural and religious perspectives, and its empathy for grieving loved ones, the AAN endorses the implicit position of the UDDA that death is a biological reality that may result from irreversible injury to the heart or brain. Accordingly, the AAN believes that death should be determined by criteria that can be objectively and uniformly assessed in order to demonstrate irreversible loss of circulatory or whole brain function, as supported by the
President's Commission. ${ }^{6,7}$ Physicians are uniquely qualified and authorized by their training, experience, and licensure to determine that death has occurred by either a circulatory or neurologic mechanism, and are professionally obligated to make this determination in a timely and accurate manner.

- Accordingly, the AAN believes that its members have both the moral authority and professional responsibility, when lawful, to perform a brain death evaluation including apnea testing, after informing a patient's loved ones or lawful surrogates of that intention, but without obligation to obtain informed consent. This position is analogous to the authority and responsibility historically granted to the medical profession to determine circulatory death without the requirement for additional informed consent. Although the AAN acknowledges the potential risk of hemodynamic instability during apnea testing, this evaluation can generally be performed safely if the prerequisites included in the guidelines are followed. ${ }^{9,32}$

- The AAN suggests that when requests for indefinite accommodation occur, all authorized stakeholders in the welfare of the patient, including members of the medical team and designated administrative or legal institutional officials, should be kept apprised of the situation. Involvement of others with recognized mediating skills, including clergy members, mental health professionals, palliative care, or ethics consultants, should be considered. ${ }^{7,22}$

- The AAN recognizes that when attempts to reconcile disputes pertaining to indefinite accommodation fail, transfer of an individual to another facility, when lawful and feasible, represents a measure of last resort.

- The AAN recognizes that when attempts to reconcile disputes pertaining to indefinite accommodation fail, unilateral withdrawal of organ-sustaining technology (other than in pregnant women) over the objection of loved ones is acceptable, when supported by law and institutional policy, and represents a measure of last resort. ${ }^{8}$ In the event that a brain-dead patient is pregnant, the ethical analysis should largely focus on the welfare of the fetus. The AAN recommends that lawful surrogates and loved ones be educated by knowledgeable professionals about relevant law as well as fetal outcome, which is often uncertain. Accordingly, in consideration of fetal welfare, the AAN endorses requests by lawful surrogates and loved ones to accommodate the prolonged use of organ-sustaining technology in a brain-dead pregnant woman of any gestational age with the following considerations. Lawful surrogates and loved ones should be fully informed by knowledgeable professionals regarding the uncertain outcome of prolonged accommodation for the fetus as well as the intention to discontinue organ-sustaining technology from the mother following completion of the pregnancy. The potential for fetal demise or severe fetal injury with or without maternal cardiopulmonary arrest should be specifically addressed. However, the AAN also endorses requests by lawful surrogates and loved ones to withdraw organ-sustaining technology if a fetus has not 
reached a viable gestational age or if a fetus of any gestational age has sustained brain injury of substantial magnitude. If a fetus has reached the age of gestational viability without brain injury of substantial magnitude, the AAN defers to the law and the conscience of the informed lawful surrogate and loved ones regarding organ-sustaining technology withdrawal decisions. Should one exist, a lawful advance directive expressing the premortal wishes of the brain dead patient regarding the care of her unborn child should be reviewed and considered subject to legal interpretation. ${ }^{12,33}$

\section{Author contributions}

James A. Russell was responsible for conception and design, drafting the manuscript, and final approval of the manuscript. All other authors were responsible for conception and design, critical revision of the manuscript, and final approval of the manuscript.

\section{Acknowledgment}

The Brain Death Working Group thanks John Hutchins, JD, Karen Kasmirski, Bruce Levi, JD, and Sarah Bird Nelson, JD, of the American Academy of Neurology Legal Office for assistance.

\section{Study funding}

The Brain Death Summit, subsequent meetings, and conference calls of the Brain Death Working Group have been financially supported by the American Academy of Neurology.

\section{Disclosure}

The authors report no disclosures relevant to the manuscript. Go to Neurology.org/N for full disclosures.

\section{Publication history}

Received by Neurology July 20, 2018. Accepted in final form September 27, 2018.

\section{References}

1. Guidelines for the determination of death: report of the medical consultants on the diagnosis of death to the President's Commission for the Study of Ethical Problems in Medicine and Biomedical and Behavioral Research. JAMA 1981;241:2184-2186.

2. President's Commission for the Study of Ethical Problems and Medicine in Biomedical and Behavioral Research. Defining Death, Medical, Ethical, and Legal Issues in the Determination of Death. Washington, DC: US Government Printing Office; 1981

3. The Uniform Determination of Death Act. Drafted by the National Conference of Commissioners on Uniform State Laws and by it approved and recommended for enactment in all the states at its annual conference meeting in its eighty-ninth year on Kauai, Hawaii; July 26-August 1, 1980. Approved by the American Medical Association October 19, 1980; approved by the American Bar Association February 10, 1981. Available at: hods.org/English/h-issues/documents/udda80.pdf. Accessed April 29, 2018.
4. The President's Council on Bioethics. Controversies in the Determination of Death; 2009. Available at: bioethicsarchive.georgetown.edu/pcbe/reports/death/. Accessed April 29, 2018.

5. Robbins MN, Bernat JL. Practice current: when do you order ancillary tests to determine brain death? Neurol Clin Pract 2018;8:266-274.

6. Lewis A, Cahn-Fuller K, Caplan A. Shouldn't dead be dead? The search for a uniform definition of death. J Law Med Ethics 2017;45:112-128.

7. Olick RS, Braun EA, Potash J. Accommodating religious and moral objections to neurologic death. J Clin Ethics 2009;20:183-191.

8. Pope TM. Legal briefing: brain death and total brain failure. J Clin Ethics 2014;25: 245-257.

9. Wijdicks EFM. Determining brain death in adults. Neurology 1995;45:1003-1011.

10. Wijdicks EFM, Varelas PN, Gronseth GS, Greer DM. Evidence-based guideline update: determining brain death in adults. Neurology 2010;74:1911-1918.

11. Nakagawa TA, Ashwal S, Mathur M, Mysore M; The Society of Critical Care Medicine, Section on Critical Care and Section on Neurology of the American Academy of Pediatrics, and the Child Neurology Society. Clinical report: guidelines for the determination of brain death in infants and children: an update of the 1987 task force recommendations. Pediatrics 2011;128:e720-e740.

12. Lewis A. Contemporary legal updates to the determination of brain death in Nevada. JAMA Neurol 2017;74:1031-1032.

13. AB 424, 79th Leg (NV 2017).

14. Lewis A, Varelas P, Greer D. Controversies after brain death: when families ask for more. Chest 2016;149:607-608.

15. Greer DM, Varelas PM, Haque S, Wijdicks EFM. Variability of brain death determination guidelines in leading US neurologic institutions. Neurology 2008;70:284-289.

16. Wang HH, Varelas PN, Henderson GV, Wijdicks EFM, Greer DM. Improving uniformity in brain death determination policies over time. Neurology 2017;88:562-568.

17. Lewis A, Adams N, Varelas P, Greer D, Caplan A. Organ support after death by neurologic criteria: results of a survey of US neurologists. Neurology 2016;87:1-8.

18. AB 424, 79th Leg (NV 2017).

19. Lewis A, Bernat JL, Blosser S, et al. An intradisciplinary response to contemporary concerns regarding brain death determination. Neurology 2018;90:423-426.

20. Nair-Collins M, Northrup J, Olcese J. Hypothalamic-pituitary function in brain death: a review. J Int Care Med 2016;31:41-50.

21. Repertinger S, Fitzgibbons WP, Omojola MF, Brumback RA. Long survival following bacterial meningitis-associated brain destruction. J Child Neurol 2006;21:591-595.

22. Lewis A, Varelas P, Greer D. Prolonging support after brain death: when families ask for more. Neurocrit Care 2016;2:481-487.

23. Wijdicks EFM. Brain death worldwide. Neurology 2002;58:20-25.

24. Shemie SD, Hornby L, Baker A, et al. International guideline development for the determination of death. Intensive Care Med 2014;40:788-797.

25. Sprung CL, Truog RD, Curtis JR, et al. Seeking worldwide professional consensus on the principles of end-of-life care for the critically ill: The Consensus for Worldwide End-of-Life Practice for Patients in Intensive Care Units (WELPICUS) study. Am J Respir Crit Care Med 2014;190:855-866.

26. Flamm AL, Smith ML, Mayer PA. Family members request to extend physiologic support after declaration of brain death: a case series analysis and proposed guidelines for clinical management. J Clin Ethics 2014;25:222-237.

27. Battro A, Bernat JL, Bousser MG, et al. Why the concept of brain death is valid as a definition of death: statement by neurologists and others: the signs of death. The Proceedings of the Working Group of 11-12 September 2006, Scripta Varia 110, The Pontifical Academy of Sciences, Vatican City 2007. Available at: vatican.va/roman curia/pontifical_academies/acdscien/index_it.htm. Accessed April 29, 2018.

28. Setta SM, Shemie SD. An explanation and analysis of how world religions formulate their ethical decisions on withdrawing treatment and determining death. Philos Ethics Humanit Med 2015;10:1-22.

29. Elpern EH, Covert B, Kleinpell R. Moral distress of staff nurses in a medical intensive care unit. Am J Crit Care 2005; 14:523-530.

30. Meltzer LS, Huckabay LM. Critical care nurses' perceptions of futile care and its effect on burnout. Am J Crit Care 2004;13:202-208.

31. Brett AS, McCullough LB. When patients request specific interventions. N Engl J Med 1986;315:1347-1351.

32. Datar S, Fugate J, Rabenstein A, Couillard P, Wijdicks EFM. Completing the apnea test: decline in complications. Neurocrit Care 2014;21:392-396.

33. Lewis A, Varelas P, Greer D. Pregnancy lack of guidance in U.S. hospital policies. Am J Perinat 2016;33:1382-1387. 


\section{Neurology}

Brain death, the determination of brain death, and member guidance for brain death accommodation requests: AAN position statement

James A. Russell, Leon G. Epstein, David M. Greer, et al.

Neurology 2019;92;228-232 Published Online before print January 2, 2019

DOI 10.1212/WNL.0000000000006750

This information is current as of January 2, 2019

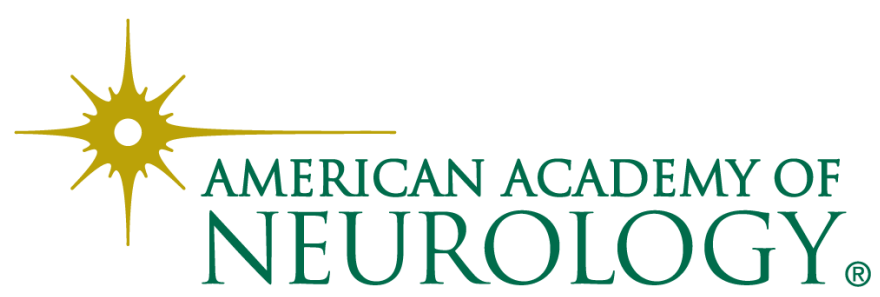




\section{Updated Information \& Services}

References

Citations

Subspecialty Collections

\section{Errata}

\section{Permissions \& Licensing}

\section{Reprints}

including high resolution figures, can be found at: http://n.neurology.org/content/92/5/228.full

This article cites 27 articles, 10 of which you can access for free at: http://n.neurology.org/content/92/5/228.full\#ref-list-1

This article has been cited by 6 HighWire-hosted articles: http://n.neurology.org/content/92/5/228.full\#\#otherarticles

This article, along with others on similar topics, appears in the following collection(s):

\section{All Ethics in Neurology/Legal issues}

http://n.neurology.org/cgi/collection/all_ethics_in_neurology_legal_iss ues

Brain death

http://n.neurology.org/cgi/collection/brain_death

Health systems

http://n.neurology.org/cgi/collection/health_systems

\section{Medical care}

http://n.neurology.org/cgi/collection/medical_care

Professional conduct and ethics

http://n.neurology.org/cgi/collection/professional_conduct_and_ethics

An erratum has been published regarding this article. Please see next page or:

/content/92/6/304.2.full.pdf

Information about reproducing this article in parts (figures,tables) or in its entirety can be found online at:

http://www.neurology.org/about/about_the_journal\#permissions

Information about ordering reprints can be found online:

http://n.neurology.org/subscribers/advertise

Neurology ${ }^{\circledR}$ is the official journal of the American Academy of Neurology. Published continuously since 1951, it is now a weekly with 48 issues per year. Copyright @ 2019 American Academy of Neurology. All rights reserved. Print ISSN: 0028-3878. Online ISSN: 1526-632X.

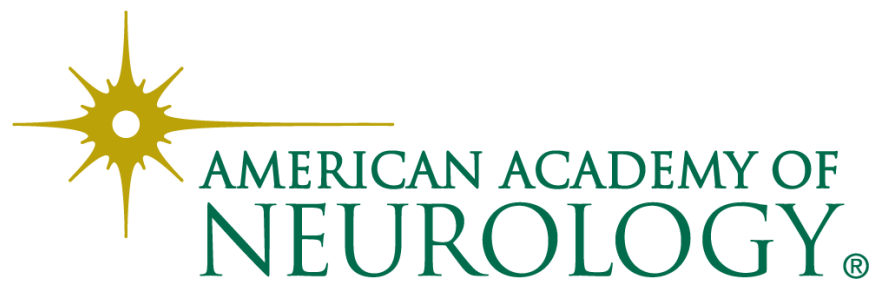




\section{Disputes \& Debates: Editors' Choice}

Steven Galetta, MD, FAAN, Section Editor

\section{Editors' note: Video Neurolmages: Paraneoplastic spinal myoclonus associated with Caspr 2 antibodies}

In their case report, Hines et al. reported spinal myoclonus as a novel neuromuscular manifestation of Caspr2 paraneoplastic disease. Caspr2 antibodies have been previously identified in conjunction with limbic encephalitis and neuromyotonia, but not in cases of spinal myoclonus. To make the diagnosis of spinal myoclonus, as Drs. Tipton, van Gerpen, and Chen appropriately acknowledge, there must be simultaneous and stereotypical activation from at least 4 muscle groups with contiguous spinal cord innervation. Given the novelty of the findings, alternative diagnoses-such as stiff-person syndrome (SPS) and the triple flexion response-must be definitively excluded. Hines et al. verify that the 2 most common SPS antibodies, GAD65 and amphiphysin, were absent from the serum, and that EMG confirmed 5 muscle groups were involved in this stereotypical response. In addition, treatment of the underlying malignancy led to resolution of motor symptoms, further implicating a pathogenic paraneoplastic process. Although the final electrographic diagnosis remains contested, this case highlights the clinical diversity of paraneoplastic disorders and the importance of accurate characterization of clinical and EMG findings in neurologic disease.

James E. Siegler III, MD, and Steven Galetta, MD

Neurology ${ }^{\circledR}$ 2019;92:302. doi:10.1212/WNL.0000000000006869

\section{Reader response: Video NeuroImages: Paraneoplastic spinal myoclonus associated with Caspr 2 antibodies}

Philip W. Tipton (Jacksonville, FL), Jay A. van Gerpen (Jacksonville, FL), and Robert Chen (Toronto, Canada) Neurology ${ }^{\circledR}$ 2019;92:302-303. doi:10.1212/WNL.0000000000006870

Hines et al. ${ }^{1}$ presented spinal myoclonus secondary to Caspr2 antibodies, including a video of intermittent right-leg jerks and an EMG tracing of activity in the rectus abdominis, purporting to show a unique EMG pattern.

We disagree with these conclusions. The clinical phenomenon is most likely a triple flexion response, an exteroceptive reflex indicative of spinal cord corticospinal tract hyperexcitability. This may occur spontaneously or be elicited by various stimuli, and is caused by multiple etiologies, including stiff-person syndrome (SPS). ${ }^{2}$ This well-described phenomenon in 2 muscles is illustrated by a surface EMG (sEMG) example (figure), which is what the figure presented by Hines et al. ${ }^{1}$ also depicts.

The accurate diagnosis of spinal myoclonus is predicated upon obtaining simultaneous sEMG recordings from at least 4 muscles to ascertain whether the pattern of muscle activation is stereotypical. Thus, definitive conclusions regarding the proper classification of the hyperkinesia in the patient presented by Hines et al. cannot be drawn, though we suspect the patient had an SPS variant (i.e., stiff-limb syndrome, a known paraneoplastic accompaniment). 


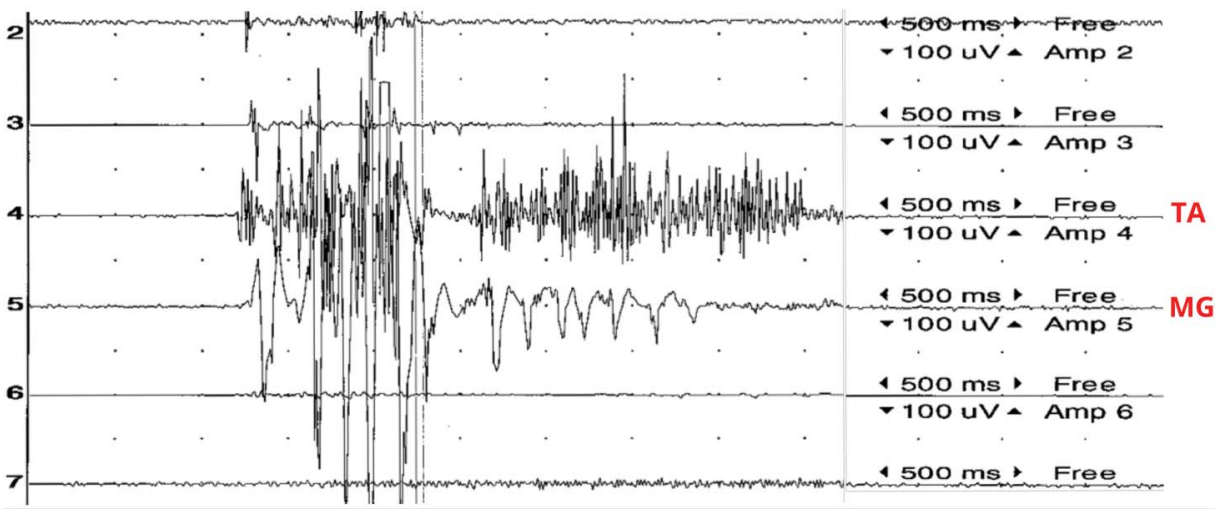

MG = medial gastrocnemius; $T A=$ tibialis anterior.

1. Hines H, Murray NM, Ahmad S, Jaradeh S, Gold CA. Video NeuroImages: Paraneoplastic spinal myoclonus associated with Caspr2 antibodies. Neurology 2018;90:660-661.

2. Espay AJ, Chen R. Rigidity and spasms from autoimmune encephalomyelopathies: stiff-person syndrome. Muscle Nerve 2006;34: $677-690$.

Copyright @ 2019 American Academy of Neurology

\section{Author response: Video NeuroImages: Paraneoplastic spinal myoclonus associated with Caspr2 antibodies}

Harrison Hines (San Francisco), Nick M. Murray (Woodside), Sarah Ahmad (Mountain View),

Safwan Jaradeh (Palo Alto), and Carl A. Gold (Stanford)

Neurology ${ }^{\circledR}$ 2019;92:303. doi:10.1212/WNL.0000000000006871

We thank Tipton et al. for their comments on our case study describing a man with spinal myoclonus associated with Caspr2 antibodies. ${ }^{1}$ We agree that determining the etiology of hyperkinesia of the lower limb in the setting of malignancy is difficult; however, we maintain our conclusions based on additional data we were unable to include in the case report due to word and format limitations.

Surface EMG studies performed in 5 muscle groups all demonstrated hyperkinesia during leg jerks that could be traced back to a spinal origin (a phenomenon that is not consistent with a triple flexion response). Serum studies were negative for GAD and amphiphysin antibodies, and the patient exhibited none of the clinical symptoms of stiff-person syndrome, such as gait abnormalities. Further work is necessary to better characterize the clinical variations associated with Caspr2 antibodies.

1. Hines H, Murray NM, Ahmad S, Jaradeh S, Gold CA. Video NeuroImages: Paraneoplastic spinal myoclonus associated with Caspr2 antibodies. Neurology 2018;90:660-661.

Copyright @ 2019 American Academy of Neurology

Author disclosures are available upon request (journal@neurology.org). 


\section{Reader response: Video NeuroImages: Paraneoplastic spinal myoclonus associated with Caspr 2 antibodies}

Philip W. Tipton (Jacksonville, FL), Jay A. van Gerpen (Jacksonville, FL), and Robert Chen (Toronto, Canada) Neurology ${ }^{\circledR}$ 2019;92:304. doi:10.1212/WNL.0000000000006872

We appreciate the response by Hines et al. ${ }^{1}$ to our skepticism that their video NeuroImage was accurately interpreted, either clinically or neurophysiologically. However, we do not find support for their conclusion that their case represents a unique form of spinal myoclonus.

The gravamen of our critique is that their patient's clinical phenomenon is an intermittent, spontaneous triple-flexion response. This exteroceptive reflex of spinal cord origin may be induced by processes that uncouple the lateral corticospinal tract from interneuron inhibition. To our knowledge, it has never been classified as a form of spinal myoclonus. ${ }^{2}$ Thus, we do not doubt the other 5 muscles they recorded from could be "traced back to spinal origin." Moreover, their presented waveform, allegedly representing a "unique form of spinal myoclonus," has the same morphology as our example of a typical exteroceptive response.

As surface EMG increasingly bolsters the accuracy of diagnosing hyperkinesias, it is imperative that the literature reflect correct surface EMG methods and interpretations.

1. Hines H, Murray NM, Ahmad S, Jaradeh S, Gold CA. Video NeuroImages: Paraneoplastic spinal myoclonus associated with Caspr2 antibodies. Neurology 2018;90:660-661.

2. Espay AJ, Chen R. Rigidity and spasms from autoimmune encephalomyelopathies: stiff-person syndrome. Muscle Nerve 2006;34: 677-690.

Copyright @ 2019 American Academy of Neurology

CORRECTION

\section{Brain death, the determination of brain death, and member guidance for brain death accommodation requests}

AAN position statement

Neurology ${ }^{\circledR}$ 2019;92:304. doi:10.1212/WNL.0000000000007117

In the Special Article "Brain death, the determination of brain death, and member guidance for brain death accommodation requests: AAN position statement," by J.A. Russell et al., ${ }^{1}$ there were errors in the byline and the inclusion of a coinvestigator list in the version published online on January 2, 2019. The byline should not have included the wording "on behalf of the Brain Death Working Group." In addition, the inclusion of a coinvestigators list was in error and the link was removed from the Footnote. The linked document was also removed. These corrections published with the final print and subsequent posting of the article on January 29, 2019. The authors regret the errors.

\section{Reference}

1. Russell JA, Epstein LG, Greer DM, Kirschen M, Rubin MA, Lewis A. Brain death, the determination of brain death, and member guidance for brain death accommodation requests: AAN position statement. Neurology 2019;92:228-232. 